\title{
Hesperidin alleviates zinc oxide nanoparticle induced hepatotoxicity and oxidative stress
}

\author{
Sabah Ansar ${ }^{1 *}$, Manal Abudawood ${ }^{1}$, Amal S. A. Alaraj ${ }^{1}$ and Sherifa S. Hamed ${ }^{2,3}$
}

\begin{abstract}
Background: Nanoparticles are widely utilized in many products such as cosmetics and sunscreens. The present study was undertaken to evaluate the effect of hesperidin (HSP) on nano zinc oxide particles (nZnO) induced oxidative stress in rat livers.

Methods: Rats were randomly divided into 4 groups of 6 rats each and exposed to single administration of nZnO intraperitoneally (600 mg/kg bwt) and HSP (100 mg/kg bwt) by gavage. Group I served as the control; group II was given $\mathrm{nZnO}$ only; groups III received HSP only and group IV received $\mathrm{nZnO} 1 \mathrm{~h}$ after pretreatment with HSP for 7 days.

Results: Compared to the controls, $\mathrm{nZnO}$ administration enhanced alanine aminotransferase (AST) and aspartate aminotransferase (ALT) levels ( $p<0.05$ ) with reduction in the levels of glutathione (GSH), catalase (CAT), glutathione peroxidase (GPX), superoxide dismutase (SOD) and increase in levels of malondialdehyde (MDA) while HSP attenuated nZnO-induced hepatotoxicity for above mentioned parameters.

Conclusions: The induced toxicity in the liver was corrected by pretreatment with HSP. The findings of this study suggest that HSP pretreatment can potentially be used to prevent $\mathrm{nZnO}$-induced biochemical alterations toxicity. Further, protection by HSP on biochemical results was confirmed by histopathological changes. The present study suggests that HSP can protect against nZnO-induced oxidative damage in the rat livers.
\end{abstract}

Keywords: Antioxidant enzymes, Zinc oxide, Metals, Nanoparticles, Hepatotoxicity

\section{Background}

Nanoparticles are widely used in medical sciences and for the making of nano based drugs for some of the incurable diseases [1]. Even though zinc is an essential trace element and is commonly present in foods or added as a nutritional supplement, it has not got much attention during assessment of toxicity of nanoparticles. However, nano size particles can cause toxicity [2], because they are highly reactive and cause oxidative stress in human and animals as they can enter the circulation and reach to different organs of the body [3-5].

Earlier studies have reported that $\mathrm{ZnO}$ nanoparticles at a high dose of $1-5 \mathrm{~g} / \mathrm{kg}$ can stimulate severe oxidative stress and cause apoptosis [6]. However, the toxicity of

\footnotetext{
* Correspondence: sansar@ksu.edu.sa

'Clinical Laboratory Sciences, Applied Medical Science, King Saud University, Riyadh, Saudi Arabia

Full list of author information is available at the end of the article
}

$\mathrm{nZnO}$ is more significant when the concentration is increased leading to toxic effects in different organs $[7,8]$. nZnOs have been also shown to be toxic to microorganisms and rodents [9] and cause inflammation, altered heart rate and function, and oxidative stress in affected parts of the body $[10,11]$. Once ingested, nanoparticles may be absorbed via intestinal lining and translocate into the blood stream and get metabolized in the liver [12]. Nanoparticles after uptake by the gastrointestinal tract get biodistributed in liver, kidney and spleen as the major organs [13].

Nanoparticles can cause oxidative stress and can lead to damage in protein structures and cause mutations [14]. Repetitive exposure to $\mathrm{nZnO}$ can induce DNA damage in human nasal mucosa and cause potential toxicity, including cytotoxic, genotoxic, and proinflammatory response $[15,16]$. The increasing use of nonmaterial's in healthcare and industrial products can lead to the possibility of their 
ingestion by humans, and other mammals. Titanium dioxide exposure can lead to toxicity and cellular responses of intestinal cells [17]. They may then translocate to blood causing adverse biological reactions in different tissues [18]. The adverse effects of silver nanoparticles (AgNPs) on the male reproductive tract, in particular spermatogenesis, and suggest that selenium can protect against AgNP-induced testicular toxicity [19].

Flavonoids are one of the most important antioxidants in fruits and vegetables, especially in the genus Citrus, as they provide health benefits through cell signaling pathways and antioxidant effects. Hesperidin (HSP, 3,5,7-trihydroxy-4-methoxy-flavanone-7-rhamnoglucoside) is a flavonone glycoside belonging to the flavonoid family acts as a potent antioxidant and anticancer agent [20]. HSP is largely isolated from citrus fruits and exhibits antioxidative, anti-inflammatory [21, 22], antihypercholesterolemic [23, 24], and antihyperglycemic [25] activities. In recent studies, beneficial effects of HSP against oxidative stress, cancer and obesity have been shown [20, 26-29]. Also, HSP significantly protected against hepatotoxicity induced by lipopolysaccharide [30], cadmium [31], acetaminophen [32], and carbon tetrachloride [33] toxicity in rats. Oxidative damage is implicated as a result of potential toxicity of nanoparticles; therefore, development of therapeutic agents with antioxidant properties is preferred. The molecular mechanisms of protection by HSP may include scavenging peroxynitrite radicals and inhibition of hydroxyl radical and reactive oxygen species (ROS). Our recent studies have shown that HSP enhances antioxidant defense with anti-inflammatory response against $\mathrm{nZnO}$-induced neurotoxicity [34]. However, little is known on antioxidative properties of HSP associated with hepatotoxicity caused by nZnO. Henceforth, the objective of this study was to investigate the protective effect of HSP against nZnO-induced oxidative stress and hepatotoxicity.

\section{Methods \\ Chemicals}

HSP powder and $\mathrm{ZnO}$ nanoparticles less than $<100 \mathrm{~nm}$ particle size and composition of $\mathrm{ZnO}>99.9 \%$ were purchased from Sigma-Aldrich, USA. ALT and AST kits and all other necessary reagents of analytical grade were bought from Sigma-Aldrich Chemicals Co., St. Louis, USA.

\section{Animals}

Twenty-four male wistar rats weighing $\sim 180-200 \mathrm{~g}$ were obtained from Pharmacy College, King Saud University. The experimental protocols were in compliance with the declarations of National Research Council [35]. Animals used in this study were placed in cages in an air conditioned room maintained with a 12-h light/ dark cycle. The rats were divided into four groups, each consisting of six animals as following groups; (1) Control rats (dimethyl sulfoxide was given as vehicle), (2) Rats received single administration of $600 \mathrm{mg} / \mathrm{kg}$ of $\mathrm{nZnO}$, (3) Rats received oral administration of $100 \mathrm{mg} / \mathrm{kg}$ of HSP for 7 days, and (4) Rats received single administration intraperitoneally (i.p.) of $600 \mathrm{mg} / \mathrm{kg}$ of $\mathrm{ZnO}$ nanoparticles $1 \mathrm{~h}$ after pretreatment with HSP for 7 days. Oral administration took place by gavage. The dose of HSP and $\mathrm{nZnO}$ used in the present study were in accordance with previous reports, respectively $[32,36]$. After $24 \mathrm{~h}$ of last treatment, the animals were euthanized (carbon dioxide was used as method of euthanasia) and blood samples were collected without using the anticoagulant and liver tissues were weighed and homogenized after adding saline. The supernatants were collected and assayed for different oxidative biomarkers.

\section{Histological examinations}

Small pieces of liver tissue were fixed directly in 10\% neutral buffered formalin.. Fixed tissues were dehydrated in ethanol, cleared in xylene, and embedded in paraffin. Tissues had been fixed in formalin for a month. Thin sections of $3 \mu \mathrm{m}$ were cut, stained with haematoxylin-eosin (H\&E) and examined under light microscope (Nikon Eclipse E600).

\section{Measurement of oxidative stress markers}

For glutathione estimation free sulphydryl content was measured as described by Ellman [37] and expressed as mmole/mg of protein. For catalase activity (CAT) [38], hydrolysis of $\mathrm{H} 2 \mathrm{O} 2$ was measured and absorbance was read at $240 \mathrm{~nm}$. It was expressed as $\mathrm{mM} / \mathrm{mg}$ protein. GPx activity [39] was monitored using $\mathrm{H}_{2} \mathrm{O}_{2}$ and the decrease of NADPH is proportional to GPx activity and expressed as $\mathrm{nM} / \mathrm{mg}$ protein.

\section{Malondialdehyde (MDA) and superoxide dismutase (SOD) assay}

Lipid peroxidation products were quantified by Draper and Hadley [40] method. In this reaction, the pink color obtained with MDA (an end product of lipid peroxidation) using TBA was determined at $535 \mathrm{~nm}$ wavelength. The results were expressed as micromoles per liter. SOD activity was determined according to the method of Sun $\mathrm{Y}$ et al. [41] described by measuring the auto-oxidation of pyrogallol at $440 \mathrm{~nm}$. The results were expressed as units per liter.

\section{Statistical analysis}

Results were analyzed using IBM SPSS software (22.0.0.0) and expressed as the mean \pm standard error of the mean (SEM). One-way ANOVA of variance was applied to test for the significance of biochemical data of the different groups followed by Duncan's multiple range test when appropriate. Results were considered significant when $p \leq 0.05$. 


\section{Results}

Intake and body weight measures

Data from these experiments showed no significant differences in food and fluid intake or body weight. Diet had no effect on mean body weight on any day.

\section{Effect on serum alanine and aspartate aminotransferase} Activities of AST and ALT were significantly increased in serum of rats treated with $\mathrm{nZnO}(p<0.05)$ as shown in Fig. 1. However, administration of HSP in nZnO-treated group caused a significant reduction in their levels. The present study indicates that HSP supplementation normalized the AST and ALT activity in serum compared to $\mathrm{nZnO}$ treated rats. Pretreatment of the rats with HSP in $\mathrm{nZnO}$-treated group caused a significant reduction in the levels of AST and ALT $(p<0.05)$. Activities of AST and ALT did not show any change in group 3 rats (HSP treated only) as compared to control group.

\section{Evaluation of biochemical parameters}

Administration of HSP led to increase in the levels of GSH and antioxidant enzyme activities of GPx and CAT when compared with $\mathrm{nZnO}$ treated group, indicating HSPs enhanced capacity to scavenge lipid hydroperoxides. A significant reduction in levels of GSH was observed in $\mathrm{nZnO}$ treated group. However, a significant increase in GSH was seen in the group with pre HSP treatment. Also group exposed to $\mathrm{nZnO}$ showed a concentration-dependent statistically significant $(p<0.05)$ decrease in antioxidant enzyme activities of GPx and CAT. However, HSP pretreatment led to increase in enzyme activities $(P<0.05)$ as shown in Table 1.

\section{Effect on superoxide dismutase (SOD) and} malondialdehyde (MDA) levels

One of the known toxic effects of free radicals is lipid peroxidation in membrane phospholipids related to the concentration of ROS generated. In this study, MDA and SOD levels were also measured. MDA levels were higher, and SOD levels were lower in $\mathrm{nZnO}$ treated group $(p<0.05$ for MDA and $p<0.05$ for SOD) when compared with those of the control group and recovery was significant in HSP pretreated group IV as compared to $\mathrm{nZnO}$ treated group II $(p<0.05$ for MDA and $p<0.05$ for SOD). However, there were no significant differences between the same parameters in HSP-alone treated group II and control group I (Fig. 2a, b).

\section{Histopathological effect}

Microscopic examination of rat livers was performed and the histopathological analysis as shown in Fig. 3. (A) highlights the hepatic histology of the control rats showing no pathological changes and cells are normal in shape and size; (B) shows the abnormal changes in the liver due to $\mathrm{nZnO}$ induced stress including disorganization of normal radiating pattern of cell plates, and degeneration of normal histopathological hepatic cells. The histopathological profile of the rats treated with HSP showed no visible changes $(C)$. The hepatic changes were protected in pretreatment with HSP in $\mathrm{ZnnO}$ treated rats (D).

\section{Discussion}

Nanoparticle exposure can damage liver which is a central organ in metabolism and detoxification and can be damaged by nanoparticle exposure [42]. Liver injury can change the level of liver enzymes such as AST, ALT which is an indicator of liver damage and liver diseases [43]. nZnOs are important metal oxide nanomaterials due to their various medicinal use and biological applications. Contact to $\mathrm{nZnO}$ induces oxidative stress and cytotoxicity in human colon carcinoma cells and induce neural stem cell apoptosis [44, 45]. Toxicity of nZnOs can be due to particle dissolution and may lead to reactive oxygen species (ROS) mediated damage [46, 47]. Also, intracellular ROS is mainly produced when the dissolved $\mathrm{Zn} 2+$ enters into the cells [48].
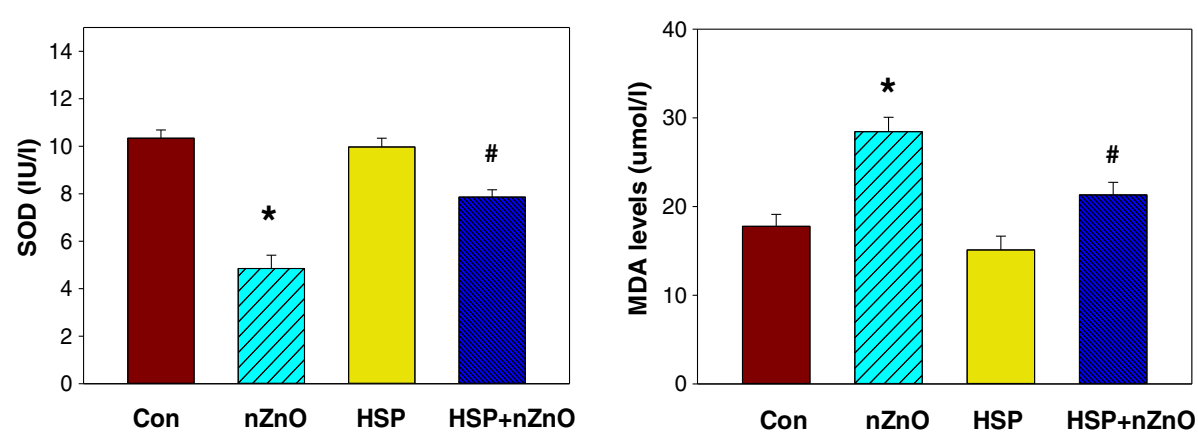

Fig. 1 Effect of HSP on nZnO-induced on serum alanine aminotransferase (AST) and aspartate aminotransferase (ALT) levels. ${ }^{*} p<0.00$ with respect to the control group. \# $p<0.003$ with respect to $n Z n O$ group and $t$ value $\left(A S T:{ }^{*} t=37.2 ;{ }^{*} P\right.$ 0.001, DF $=1,11: \# t=70.5 ; \# P$ 0.001, $\mathrm{DF}=1,11: \mathrm{ALT}:{ }^{*} t=53.7 ;{ }^{*} \mathrm{P} 0.001, \mathrm{DF}=1,11: \# t=43.74 ; \# \mathrm{P} 0.001, \mathrm{DF}=1,11$ ) 

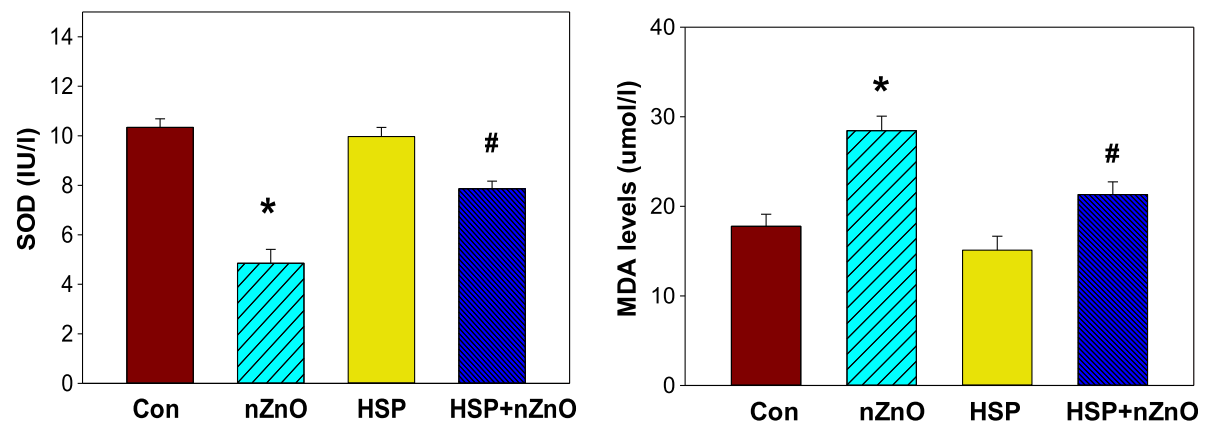

Fig. 2 Effect of $n Z n O$ on the oxidative stress markers (a) superoxide dismutase level (b) Malonaldehyde level. ${ }^{*} p<0.004$, compared to control group. \# $p<0.001$, compared to $\mathrm{nZnO}$ group and $\mathrm{t}$ value (SOD: ${ }^{*} t=32.2 ;{ }^{* P} 0.001, \mathrm{DF}=1,11$ : $\# t=78.1$; $\# \mathrm{P} 0.001, \mathrm{DF}=1,11: \mathrm{MDA}:{ }^{*} t=50.7 ;{ }^{*} \mathrm{P}$ $0.001, \mathrm{DF}=1,11: \# \mathrm{t}=70.5 ; \# \mathrm{P} 0.001, \mathrm{DF}=1,11)$

An important aspect of the $\mathrm{nZnO}$ use is the requirement that they should not be cytotoxic to the body. Previous studies showed that formation of ROS was responsible for cellular toxicity and the discharge of $\mathrm{Zn}$ + ions from the nZnOs, due to their instability in lysosomes which have acidic compartment leading to increase in the ROS generation [47].

Earlier studies have shown that $\mathrm{nZnO}$ exposure lead to MDA content increase in the zebra fish [49]. MDA is one of the main products of lipid peroxidation and can react with DNA bases [50]. It was observed earlier that oxidative effect of $\mathrm{nZnO}$ was much more than other non-metal nanoparticles [51]. Zhao et al. (2013) showed that nZnOs stimulates developmental toxicity, oxidative stress, and DNA damage on zebra fish embryos and may be partly due to the dissolved $\mathrm{Zn}^{2+}$ [49]. In this study, treatment with $\mathrm{nZnO}$ showed MDA levels higher, and SOD levels lower. However, pretreatment with HSP led to decrease in MDA levels and increase in SOD levels. Tissue lipid peroxide content is the most important marker of oxidative stress. HSP alone had no effect in this study given the basal levels of MDA are robust; indicating a detectable amount of lipid peroxidation is ongoing under basal conditions. HSP, which is an antioxidant and anti-inflammatory agent, could be that pretreatment with HSP protected the tissue against free radical damage. Reduction in the SOD level was also found on $24 \mathrm{~h}$ exposure of human embryonic kidney cells to nZnOs [52].
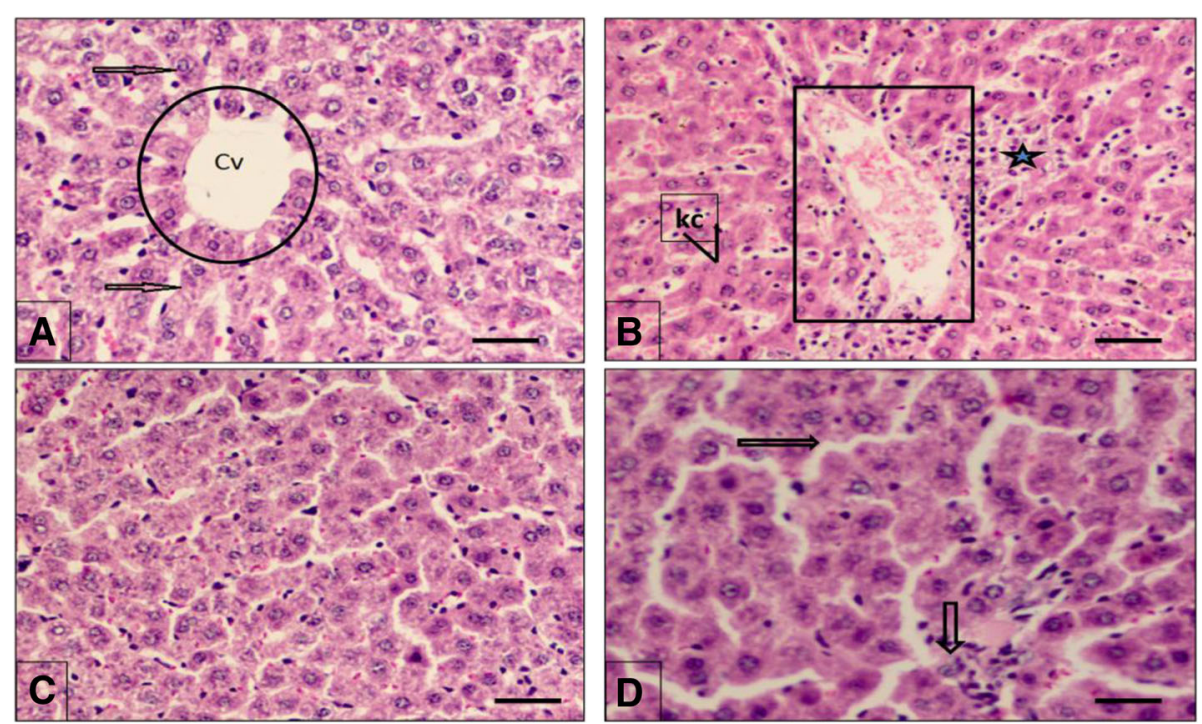

Fig. 3 Effect of HSP and nZnO on the histology of rat livers: a Control group, showing normal liver architecture showing portal area (circle), hepatic strands of eosinophils (arrow), central vein (CV). $\mathbf{b} \mathrm{nZnO}$ treated group showing portal tract expansion (square), hyalinization of hepatocytes, and dense infiltration of mononuclear cells (asterisks'), increase of Kupffur cell (kc), accumulation of cells around central vein. c Section of rat liver (HSP treated) showing normal hepatocytes and central vein (CV) similar to control. $\mathbf{d}$ Section of rat livers (HSP+ nZnO treated) showing normal cellular appearance and decrease in toxicity (arrow). Scale bar $50 \mu \mathrm{m}$. H \& E stain 
Table 1 HSP protects ROS -mediated toxicity induced by $\mathrm{nZnO}$

\begin{tabular}{lllll}
\hline EXPERIMENTAL GROUPS & & & \\
\hline Parameters & Control (I) & $\mathrm{n} \mathrm{ZnO} \mathrm{(II)}$ & HSP (III) & $\begin{array}{l}\text { HSP }+\mathrm{nZnO} \\
(\mathrm{IV})\end{array}$ \\
\hline $\begin{array}{l}\text { GSH (mmol/mg } \\
\text { prot) }\end{array}$ & $1.08 \pm 0.02$ & $0.97 . \pm 0.01^{*}$ & $1.12 \pm 0.06$ & $1.47 \pm 0.04^{* *}$ \\
CAT (IU/mg prot) & $1.95 \pm 0.11$ & $0.91 \pm 0.14^{*}$ & $1.82 \pm 0.11$ & $1.45 \pm 0.14^{* *}$ \\
GPx (U/mg prot) & $1.13 \pm 0.01$ & $0.54 \pm 0.07^{*}$ & $1.11 \pm 0.05$ & $0.95 \pm 0.02^{* *}$
\end{tabular}

All values are mean \pm SEM, $n=6 ; *$ I vs. II $\left({ }^{*} P<0.05\right)$. II vs. IV $(* * P<0.05)$ GSH: ${ }^{*} t=6.133 ;{ }^{* P} 0.002, \mathrm{DF}=5,11:{ }^{* *} t=4.45 ;{ }^{* * P} 0.007, \mathrm{DF}=5,11 / \mathrm{CAT}:{ }^{*} t=$ 49.2; ${ }^{* P} 0.001, \mathrm{DF}=1,11:{ }^{* *} t=41.6$; ${ }^{*} \mathrm{P} 0.001, \mathrm{DF}=1,11 / \mathrm{GPx}:{ }^{*} t=33.13$; ${ }^{*} \mathrm{P}$ $0.002, \mathrm{DF}=1,11:{ }^{* *} \mathrm{t}=43.74 ;{ }^{* * \mathrm{P}} 0.001, \mathrm{DF}=1,11$

Exposure of endothelial cells to different nanoparticles causes tissue toxicity depending on its composition and concentration [53, 54]. Gojova et al. (2007) showed that nanoparticles stimulated inflammation and lead to production of ROS [53]. Also, it has been reported that exposure to $100 \mathrm{mg} / \mathrm{L}$ of $\mathrm{nZnO}$ caused a significant inhibition of SOD activity and more production of ROS and [49]. As levels of ROS produced by $\mathrm{nZnOs}$ exceed the capacity of cellular antioxidants, the antioxidant system cannot eliminate them. nZnO also has an inhibitory effect on CAT activity, which suggests that $\mathrm{H}_{2} \mathrm{O}_{2}$ generated by SOD cannot be removed completely by CAT directly and may cause intracellular buildup of ROS. Overall, we observed significant depletion in activities of antioxidant enzymes and GSH levels and significant increase in ALT, AST and MDA levels in rat liver tissue and this effect was reversed by the supplementation of HSP.

Recent histopathological studies demonstrated apoptosis in the pancreas, inflammation, edema, and retinal atrophy of the eye in the $500 \mathrm{mg} / \mathrm{kg}$ of $\mathrm{nZnO}$ treated group [55]. The present study showed abnormal changes including disorganization of normal radiating pattern of cell plates, and degeneration of normal hepatic cells in the liver due to $\mathrm{nZnO}$ induced stress. However, it was protected by pretreatment with $\mathrm{HSP}$ in $\mathrm{nZnO}$ treated rats. It has also been shown that nZnOs can cause various pathologic changes in the target organs with increased tubular deformations, necrosis and cytoplasmic vacuolations in the kidney, the edema, mononuclear cell infiltrations, and, the pyknotic nuclei in the liver [56].

\section{Conclusions}

In conclusion, this study shows that HSP decreases liver toxicity in rats and that its effect is mediated by antioxidant activities. Results in this study suggest that HSP helps in reducing the hepatotoxicity of $\mathrm{nZnO}$ as also indicated by protection of histopathological changes in tissue. Future studies should examine the fact that HSP therapy targeted to liver toxicity may constitute an interesting strategy to reduce hepatotoxicity at molecular level.

\section{Abbreviations}

AgNP: Silver nanoparticles; ALT: Alanine aminotransferase; AST: Aspartate aminotransferas; CAT: Catalase; DF: Degree of freedom; DMSO: Dimethyl sulfoxide; GPx: Glutathione peroxidase; GSH: Glutathione; HSP: Hesperidin; MDA: Malondialdehyde; nZnO: Nano zinc oxide particles; ROS: Reactive oxygen species; SOD: Superoxide dismutase

\section{Acknowledgements}

Authors also thank Ms. Sarah Farhat for editing and preparation of the manuscript and Ms. Jocelyn Palao for her help in the preparation of histological samples.

\section{Funding}

The authors extend their appreciation to the Deanship of Scientific Research, King Saud University for funding this work through the Undergraduate Student's Research Support Program (ursp-3-17-21).

\section{Availability of data and materials}

The datasets used and/or analyzed during the current study are available from the corresponding author on reasonable request.

\section{Authors' contributions}

MA and SA were involved in drafting the manuscript and revising it critically. They were also involved in substantial contributions to conception and study design. ASAA carried out the experimental work. SH helped with analysis and interpretation of data. All authors have read and approved the final manuscript.

\section{Ethics approval}

The study was conducted according to the national guidelines for the Care and Use of Laboratory Animals. All protocols were approved by the College of Applied Medical Sciences Ethics Committee of King Saud University.

\section{Consent for publication}

Not applicable in this section.

\section{Competing interests}

The authors declare that they have no competing interests.

\section{Publisher's Note}

Springer Nature remains neutral with regard to jurisdictional claims in published maps and institutional affiliations.

\section{Author details}

${ }^{1}$ Clinical Laboratory Sciences, Applied Medical Science, King Saud University, Riyadh, Saudi Arabia. '2Zoology Department, College of Science, King Saud University, Riyadh, Saudi Arabia. ${ }^{3}$ Zoology Department, Faculty of Science, University of Alexandria, Moharram Bey, Alexandria 21511, Egypt.

Received: 26 April 2017 Accepted: 3 October 2018

Published online: 19 October 2018

\section{References}

1. Jani P, Halbert GW, Langridge J, Florence AT. Nanoparticle uptake by the rat gastrointestinal mucosa: quantitation and particle size dependency. J Pharm Pharmacol. 1990;42(12):821-6.

2. Srivastav AK, Kumar M, Ansari NG, Jain AK, Shankar J, Arjaria N, Jagdale P, Singh D. A comprehensive toxicity study of zinc oxide nanoparticles versus their bulk in Wistar rats: toxicity study of zinc oxide nanoparticles. Hum Exp Toxicol. 2016:35:1286-304.

3. Koziara JM, Lockman PR, Allen DD, Mumper RJ. In situ blood-brain barrier transport of nanoparticles. Pharm Res. 2003;20(11):1772-8.

4. Lockman PR, Oyewumi MO, Koziara JM, Roder KE, Mumper RJ, Allen DD. Brain uptake of thiamine-coated nanoparticles. J Control Release. 2003;93(3):271-82.

5. Barbu E, Molnar E, Tsibouklis J, Gorecki DC. The potential for nanoparticlebased drug delivery to the brain: overcoming the blood-brain barrier. Expert Opin Drug Deliv. 2009;6(6):553-65.

6. Sharma V, Singh P, Pandey AK, Dhawan A. Induction of oxidative stress, DNA damage and apoptosis in mouse liver after sub-acute oral exposure to zinc oxide nanoparticles. Mutat Res. 2012;745(1-2):84-91. 
7. Abbasalipourkabir R, Moradi H, Zarei S, Asadi S, Salehzadeh A, Ghafourikhosroshahi A, Mortazavi M, Ziamajidi N. Toxicity of zinc oxide nanoparticles on adult male Wistar rats. Food Chem Toxicol. 2015;84:154-60.

8. Plum LM, Rink $L$, Haase $H$. The essential toxin: impact of zinc on human health. Int J Environ Res Public Health. 2010;7(4):1342-65.

9. Pujalte I, Passagne I, Brouillaud B, Treguer M, Durand E, Ohayon-Courtes C, L'Azou B. Cytotoxicity and oxidative stress induced by different metallic nanoparticles on human kidney cells. Part Fibre Toxicol. 2011;8:10.

10. Campen MJ, McDonald JD, Gigliotti AP, Seilkop SK, Reed MD, Benson JM. Cardiovascular effects of inhaled diesel exhaust in spontaneously hypertensive rats. Cardiovasc Toxicol. 2003;3(4):353-61.

11. Campbell A, Oldham M, Becaria A, Bondy SC, Meacher D, Sioutas C, Misra C, Mendez LB, Kleinman M. Particulate matter in polluted air may increase biomarkers of inflammation in mouse brain. Neurotoxicology. 2005;26(1):133-40.

12. Bockmann J, Lahl H, Eckert T, Unterhalt B. Titanium blood levels of dialysis patients compared to healthy volunteers. Pharmazie. 2000;55(6):468.

13. Cui Y, Liu H, Zhou M, Duan Y, Li N, Gong X, Hu R, Hong M, Hong F. Signaling pathway of inflammatory responses in the mouse liver caused by TiO2 nanoparticles. J Biomed Mater Res A. 2011;96(1):221-9.

14. Bystrzejewska-Piotrowska G, Golimowski J, Urban PL. Nanoparticles: their potential toxicity, waste and environmental management. Waste Manag. 2009;29(9):2587-95.

15. Hackenberg S, Zimmermann FZ, Scherzed A, Friehs G, Froelich K, Ginzkey C, Koehler C, Burghartz M, Hagen R, Kleinsasser N. Repetitive exposure to zinc oxide nanoparticles induces dna damage in human nasal mucosa mini organ cultures. Environ Mol Mutagen. 2011;52(7):582-9.

16. Teow Y, Asharani PV, Hande MP, Valiyaveettil S. Health impact and safety of engineered nanomaterials. Chem Commun (Camb). 2011;47(25):7025-38.

17. Koeneman BA, Zhang Y, Westerhoff P, Chen Y, Crittenden JC, Capco DG Toxicity and cellular responses of intestinal cells exposed to titanium dioxide. Cell Biol Toxicol. 2010;26(3):225-38.

18. Johnston HJ, Hutchison G, Christensen FM, Peters S, Hankin S, Stone V. A review of the in vivo and in vitro toxicity of silver and gold particulates: particle attributes and biological mechanisms responsible for the observed toxicity. Crit Rev Toxicol. 2010:40(4):328-46.

19. Ansar S, Abudawood M, Hamed SS, Aleem MM. Sodium selenite protects against silver nanoparticle-induced testicular toxicity and inflammation. Biol Trace Elem Res. 2017;175(1):161-8.

20. Ahmadi A, Shadboorestan A. Oxidative stress and cancer; the role of hesperidin, a citrus natural bioflavonoid, as a cancer chemoprotective agent. Nutr Cancer. 2016;68(1):29-39.

21. Hosseinimehr SJ, Jalayer Z, Naghshvar F, Mahmoudzadeh A. Hesperidin inhibits cyclophosphamide-induced tumor growth delay in mice. Integr Cancer Ther. 2012;11(3):251-6.

22. Mahmoud AM, Ashour MB, Abdel-Moneim A, Ahmed OM. Hesperidin and naringin attenuate hyperglycemia-mediated oxidative stress and proinflammatory cytokine production in high fat fed/streptozotocin-induced type 2 diabetic rats. J Diabetes Complicat. 2012;26(6):483-90.

23. Koyuncu H, Berkarda B, Baykut F, Soybir G, Alatli C, Gul H, Altun M. Preventive effect of hesperidin against inflammation in CD-1 mouse skin caused by tumor promoter. Anticancer Res. 1999;19(4B):3237-41.

24. Crespo ME, Galvez J, Cruz T, Ocete MA, Zarzuelo A. Anti-inflammatory activity of diosmin and hesperidin in rat colitis induced by TNBS. Planta Med. 1999:65(7):651-3.

25. Zhang B, Chen T, Chen Z, Wang M, Zheng D, Wu J, Jiang X, Li X. Synthesis and anti-hyperglycemic activity of hesperidin derivatives. Bioorg Med Chem Lett. 2012;22(23):7194-7.

26. Hewage SR, Piao MJ, Kang KA, Ryu YS, Han X, Oh MC, Jung U, Kim IG, Hyun JW. Hesperidin attenuates ultraviolet B-induced apoptosis by mitigating oxidative stress in human keratinocytes. Biomol Ther (Seoul). 2016:24:312-9.

27. Ohara T, Muroyama K, Yamamoto Y, Murosaki S. Oral intake of a combination of glucosyl hesperidin and caffeine elicits an anti-obesity effect in healthy, moderately obese subjects: a randomized double-blind placebocontrolled trial. Nutr J. 2016;15(1):6.

28. Oguzturk H, Ciftci O, Cetin A, Kaya K, Disli OM, Turtay MG, Gurbuz S, Basak $\mathrm{N}$. Beneficial effects of hesperidin following cis-diamminedichloroplatinuminduced damage in heart of rats. Niger J Clin Pract. 2016;19(1):99-103.

29. Polat N, Ciftci O, Cetin A, Yilmaz T. Toxic effects of systemic cisplatin on rat eyes and the protective effect of hesperidin against this toxicity. Cutan Ocul Toxicol. 2016;35(1):1-7.
30. Kaur G, Tirkey N, Chopra K. Beneficial effect of hesperidin on lipopolysaccharide-induced hepatotoxicity. Toxicology. 2006;226(2-3):152-60.

31. Pari L, Shagirtha K. Hesperetin protects against oxidative stress related hepatic dysfunction by cadmium in rats. Exp Toxicol Pathol. 2012;64(5):513-20.

32. Ahmad ST, Arjumand W, Nafees S, Seth A, Ali N, Rashid S, Sultana S. Hesperidin alleviates acetaminophen induced toxicity in Wistar rats by abrogation of oxidative stress, apoptosis and inflammation. Toxicol Lett. 2012;208(2):149-61.

33. Yeh YH, Hsieh YL, Lee YT. Effects of yam peel extract against carbon tetrachlorideinduced hepatotoxicity in rats. J Agric Food Chem. 2013;61(30):7387-96.

34. Ansar S, Abudawood M, Hamed SS, Aleem MM. Exposure to zinc oxide nanoparticles induces neurotoxicity and Proinflammatory response: amelioration by hesperidin. Biol Trace Elem Res. 2016;175:360-k6.

35. Derrell C. Guide for the care and use of laboratory animals. Institute of Laboratory Animal Resources. Washington DC: National Academy Press; 1996.

36. Wang B, Feng WY, Wang TC, Jia G, Wang M, Shi JW, Zhang F, Zhao YL, Chai ZF. Acute toxicity of nano- and micro-scale zinc powder in healthy adult mice. Toxicol Lett. 2006;161(2):115-23.

37. Ellman GL. Tissue sulfhydryl groups. Arch Biochem Biophys. 1959;82(1):70-7.

38. Aebi H. Catalase in vitro. Methods Enzymol. 1984;105:121-6.

39. Paglia $D E$, Valentine $W N$. Studies on the quantitative and qualitative characterization of erythrocyte glutathione peroxidase. J Lab Clin Med. 1967; 70(1):158-69.

40. Draper $\mathrm{HH}$, Hadley M. Malondialdehyde determination as index of lipid peroxidation. Methods Enzymol. 1990;186:421-31.

41. Sun Y, Oberley LW, Li Y. A simple method for clinical assay of superoxide dismutase. Clin Chem. 1988;34(3):497-500.

42. Meyer SA. Overview of hepatotoxicity. Curr Protoc Toxicol. 2001;14:11 Chapter 14: Unit.

43. Fu Y, Zheng S, Lin J, Ryerse J, Chen A. Curcumin protects the rat liver from CCl4-caused injury and fibrogenesis by attenuating oxidative stress and suppressing inflammation. Mol Pharmacol. 2008;73(2):399-409.

44. De Berardis B, Civitelli G, Condello M, Lista P, Pozzi R, Arancia G, Meschini S. Exposure to $\mathrm{ZnO}$ nanoparticles induces oxidative stress and cytotoxicity in human colon carcinoma cells. Toxicol Appl Pharmacol. 2010;246(3):116-27.

45. Deng X, Luan Q, Chen W, Wang Y, Wu M, Zhang H, Jiao Z. Nanosized zinc oxide particles induce neural stem cell apoptosis. Nanotechnology. 2009;20(11):115101.

46. Ma H, Williams PL, Diamond SA. Ecotoxicity of manufactured $\mathrm{ZnO}$ nanoparticles--a review. Environ Pollut. 2013;172:76-85.

47. Zabirnyk O, Yezhelyev M, Seleverstov O. Nanoparticles as a novel class of autophagy activators. Autophagy. 2007;3(3):278-81.

48. Yin $Y$, Lin $Q$, Sun $H$, Chen D, Wu Q, Chen X, Li S. Cytotoxic effects of $\mathrm{ZnO}$ hierarchical architectures on RSC96 Schwann cells. Nanoscale Res Lett. 2012;7:439.

49. Zhao X, Wang S, Wu Y, You H, Lv L. Acute ZnO nanoparticles exposure induces developmental toxicity, oxidative stress and DNA damage in embryo-larval zebrafish. Aquat Toxicol. 2013;136-137:49-59.

50. Marnett L. Oxy radicals, lipid peroxidation and DNA damage. Toxicology. 2002;181-182:219-22.

51. Yang H, Liu C, Yang D, Zhang H, Xi Z. Comparative study of cytotoxicity, oxidative stress and genotoxicity induced by four typical nanomaterials: the role of particle size, shape and composition. J Appl Toxicol. 2009;29(1):69-78.

52. Horie M, Nishio K, Fujita K, Endoh S, Miyauchi A, Saito Y, Iwahashi H, Yamamoto K, Murayama $\mathrm{H}$, Nakano $\mathrm{H}$, et al. Protein adsorption of ultrafine metal oxide and its influence on cytotoxicity toward cultured cells. Chem Res Toxicol. 2009;22(3):543-53.

53. Gojova A, Guo B, Kota RS, Rutledge JC, Kennedy IM, Barakat Al. Induction of inflammation in vascular endothelial cells by metal oxide nanoparticles: effect of particle composition. Environ Health Perspect. 2007:115(3):403-9.

54. Peters K, Unger RE, Kirkpatrick CJ, Gatti AM, Monari E. Effects of nano-scaled particles on endothelial cell function in vitro: studies on viability, proliferation and inflammation. J Mater Sci Mater Med. 2004;15(4):321-5.

55. Park HS, Kim SJ, Lee TJ, Kim GY, Meang E, Hong JS, Kim SH, Koh SB, Hong SG, Sun YS, et al. A 90-day study of sub-chronic oral toxicity of $20 \mathrm{~nm}$ positively charged zinc oxide nanoparticles in Sprague Dawley rats. Int J Nanomedicine. 2014:9(Suppl 2):93-107.

56. Kaya H, Aydin F, Gurkan M, Yilmaz S, Ates M, Demir V, Arslan Z. A comparative toxicity study between small and large size zinc oxide nanoparticles in tilapia (Oreochromis niloticus): organ pathologies, osmoregulatory responses and immunological parameters. Chemosphere. 2016;144:571-82. 